\title{
Multicomponent crystals of mefenamic acid-tromethamine with improved dissolution rate
}

\author{
Yori YULIANDRA ${ }^{1}(\mathbb{D})$, Riri IZADIHARI ${ }^{2}$ (D) , Henni ROSAINI ${ }^{2}(\mathbb{D})$, Erizal ZAINI ${ }^{1}$ * (D) \\ 1 Faculty of Pharmacy, Andalas University, Padang 25163, Indonesia. \\ 2 School of Pharmaceutical Sciences Padang (STIFARM), Padang 26163, Indonesia. \\ * Corresponding Author. E-mail: erizal@phar.unand.ac.id (E.Z.); Tel. +62 75171682.
}

Received: 22 February 2019 / Revised: 2 May 2019 / Accepted: 9 May 2019

\begin{abstract}
Mefenamic acid (MA) is a popular nonsteroidal anti-inflammatory drug classified into BCS class II which has a low solubility and dissolution rate in an aqueous medium. The present study aimed to improve the dissolution rate of MA by preparing multicomponent crystals with tromethamine (TM) through the solvent evaporation technique. The resulting powder was characterized for its solid-state properties and evaluated for the dissolution rate. The results showed that the powder X-ray diffraction pattern of the MA-TM binary system was different from its starting materials, indicating the formation of a new crystalline phase. The differential scanning calorimetry analysis of the MA-TM binary system showed a single and sharp endothermic peak at $110^{\circ} \mathrm{C}$, which was attributed to the melting point of MA-TM multicomponent crystals. The Fourier transform infrared spectroscopy analysis showed the occurrence of solid-state interaction involving proton transfer between MA and TM. The dissolution efficiency of MA-TM multicomponent crystal was 2.5-fold higher than the intact MA. The study concludes that the MA-TM binary system forms a salt-type multicomponent crystal. The multicomponent crystals can significantly increase its dissolution rate and is an alternative technique for modifying the physicochemical properties of active pharmaceutical ingredients.
\end{abstract}

KEYWORDS: Mefenamic acid; tromethamine; multicomponent crystal; dissolution rate.

\section{INTRODUCTION}

Mefenamic acid (MA) is an active pharmaceutical ingredient that has anti-inflammatory and analgesic activities. It is used clinically to relieve mild to moderate pain and in the treatment of rheumatoid arthritis [1]. In addition, MA is also reported to exhibit a neuroprotective effect [2]. This drug is classified into BCS class II, according to the biopharmaceutical classification system which is a drug with low solubility and high permeability [3,4]. Low drug solubility in water will cause low absorption of drugs in the gastrointestinal fluid. To optimize the absorption and, thus, the bioavailability of MA in the systemic circulation, it is critical to improving its dissolution rate in aqueous medium $[5,6]$. Several studies have been carried out to improve the solubility and dissolution rate of MA, including reduction of particle size, formation of solid dispersion, complexes inclusion, self-emulsifying formulation, molecular complexes, nanocrystals formation, the addition of surfactants, spray drying and freeze drying technique [4,7-14].

Solid-state properties of drug compounds significantly influence their physicochemical properties and bioavailability $[15,16]$. One of the interesting strategies to change the solid-state properties to improve solubility and dissolution rate is the formation of a multicomponent phase by crystal engineering techniques [17]. Multicomponent crystals of pharmaceutical materials consist of co-crystal, salt, hydrate and solvate. Modification of physicochemical properties of an active pharmaceutical ingredient (API) via crystal engineering has become a popular approach because this approach can improve solubility, dissolution rate, compressibility, physical and chemical stability and pharmacological effectiveness [18-22].

Our previous finding has shown that MA can form salt type multicomponent crystal with N-Methyl-DGlucamine with improved the dissolution rate and physical stability [22]. In the current study, we prepared multicomponent crystals of MA (Fig. 1A) with tromethamine (TM) (Fig. 1B) by the solvent evaporation technique. TM is a GRAS (generally recognized as safe) excipient according to FDA (the US Food and Drug Administration) and is widely used as an alkalizer and biological buffer. Moreover, TM is also used as a salt co-former for some weak acid drugs to improve the physicochemical properties [23,24]. To our knowledge,

How to cite this article: Yuliandra Y, Izadihari R, Rosaini H, Zaini E. Multicomponent crystals of mefenamic acid-tromethamine with improved dissolution rate. J Res Pharm. 2019; 23(6): 988-996. 
there is no report on the formation of the multicomponent crystal of MA-TM so far. The present study aimed to improve the dissolution rate of MA through crystal engineering technique and characterize the solid-state properties of the multicomponent crystal of MA-TM by scanning electron microscopy (SEM), powder X-ray diffraction analysis (PXRD), differential scanning calorimetry (DSC) thermal analysis, and Fourier transform infrared (FT-IR) spectroscopy.<smiles>Cc1cccc(Nc2ccccc2C(=O)O)c1C</smiles>

(A)<smiles>NC(CO)(CO)CO</smiles>

(B)

Figure 1. Molecular structures of (A) Mefenamic acid and (B) Tromethamine.

\section{RESULTS AND DISCUSSION}

The initial evaluation of the multicomponent crystal phase is the crystal habit using an SEM microscope apparatus. The crystallization process of the API from various solvents can produce different crystal habit, polymorphs and particle sizes. Crystal habit is one of the essential physicochemical properties in the manufacturing process. The crystal habit will affect the flowability, compressibility, dissolution rate and bulk density of the API particles $[25,26]$. In most cases, the solid-state interaction of the binary system API with excipients often produces a new crystal habit that is different from its forming compounds [27,28]. Fig. 2 demonstrates a crystal habit of mefenamic acid (MA), tromethamine (TM) and multicomponent crystals of MA-TM. MA is irregularly shaped solid particles, and TM shows large spherical particles. Meanwhile, the multicomponent crystals of MA-TA indicate a new crystal habit as fine needle-shaped particles.
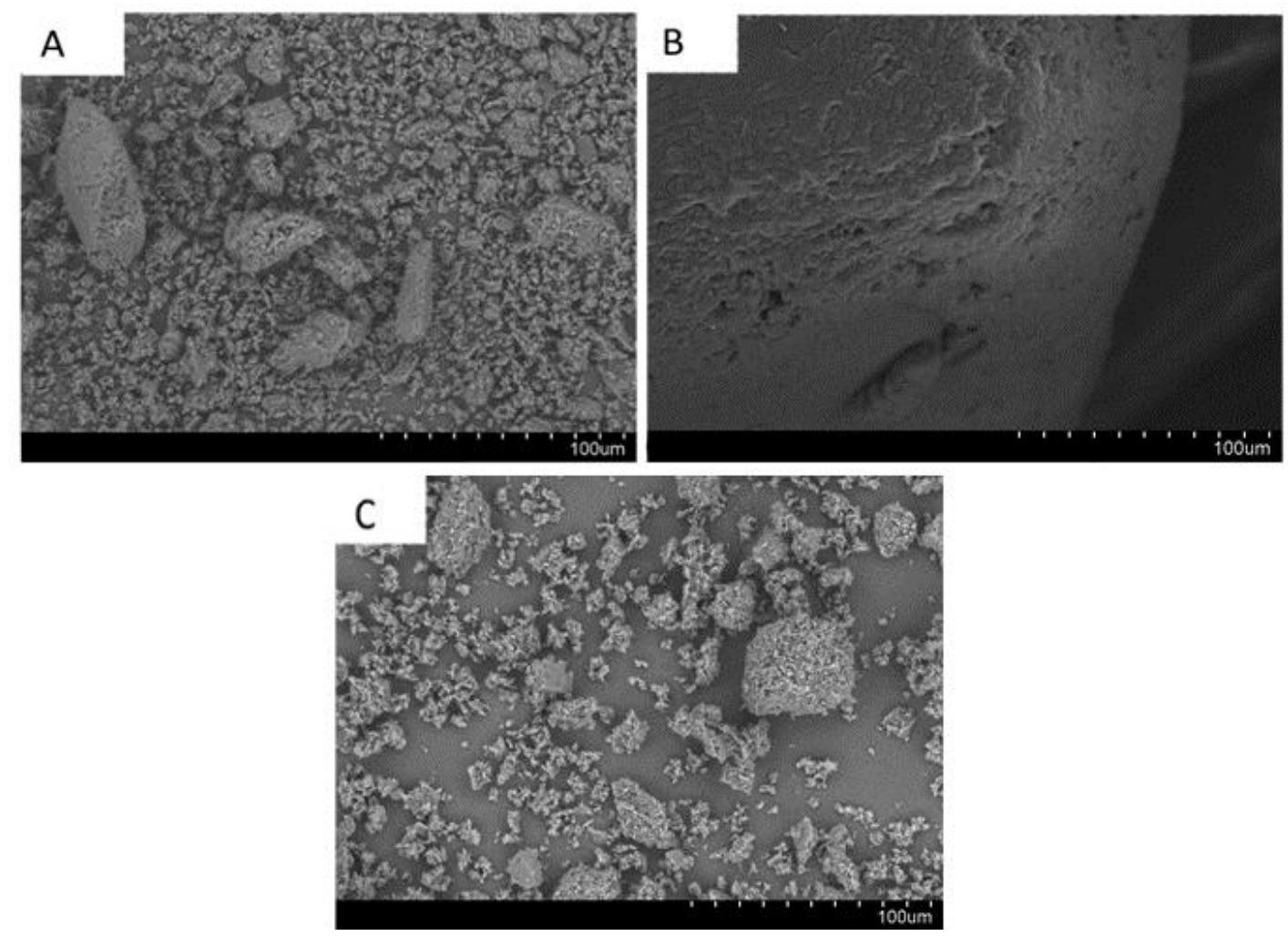

Figure 2. Scanning electron micrographs of (A) mefenamic acid; (B) tromethamine; and (C) Multicomponent crystal of mefenamic acid-tromethamine (all images at $500 \times$ magnification). 
PXRD analysis is a reliable technique for determining the degree of crystallinity and the formation of new crystalline phases. Each solid crystalline phase has a distinctive diffraction pattern which can be used as a fingerprint for each crystalline phase [29]. The PXRD patterns of MA, TM and multicomponent crystals MATM are presented in Fig. 3. MA is a crystalline solid with sharp diffraction peaks at $2 \theta=13.84,15.03,15.65$, $20.02,21.21,26.03,27.67,31.24$ and $31.87^{\circ}$. The MA diffractogram shows the polymorph I as reported by a previous study [30]. TM also has a high degree of crystallinity, with typical diffraction peaks at $2 \theta=14.01$, $18.09,20.13,22.40,25.06,26.76$ and $33.79^{\circ}$. On the other hand, the diffractogram of the physical mixture of MATM is only a superimposition of the interference peaks of MA and TM. Furthermore, the diffractogram of MC shows a distinct pattern which is different from intact MA and TM. Some new diffraction peaks appear at $2 \theta$ $=11.85,17.52,19.56,21.60,23.42$ and $29.37^{\circ}$. This result proves that a multicomponent crystal phase is formed between MA and TM in the equimolar ratio (1:1). The multicomponent crystals include cocrystals, salt, solvate and hydrate. The $\mathrm{p} K_{\mathrm{a}}$ rule can be one of the guidelines for predicting whether the interactions between the two solid phases (active pharmaceutical ingredients and excipients) form either a cocrystalline phase or salt. The cocrystalline phase is likely to be formed if the $\mathrm{p} K_{\mathrm{a}}$ difference between the API and the excipient $<2$. Whereas, if the $\mathrm{p} K_{\mathrm{a}}$ difference $>3$, then it can form a salt-type multicomponent crystal [31,32]. The $\mathrm{p} K_{\mathrm{a}} \mathrm{s}$ of MA and TM are reported as 4.2 and 8.07 , respectively $[11,33]$. In the present study, the difference in $\mathrm{p} K_{\mathrm{a}}$ between these two solid phases is $3.87(>3)$. Based on the $\Delta \mathrm{p} K_{\mathrm{a}}$ rule it can be assumed that the interaction between MA and TM is through the formation of salt-type multicomponent crystals.

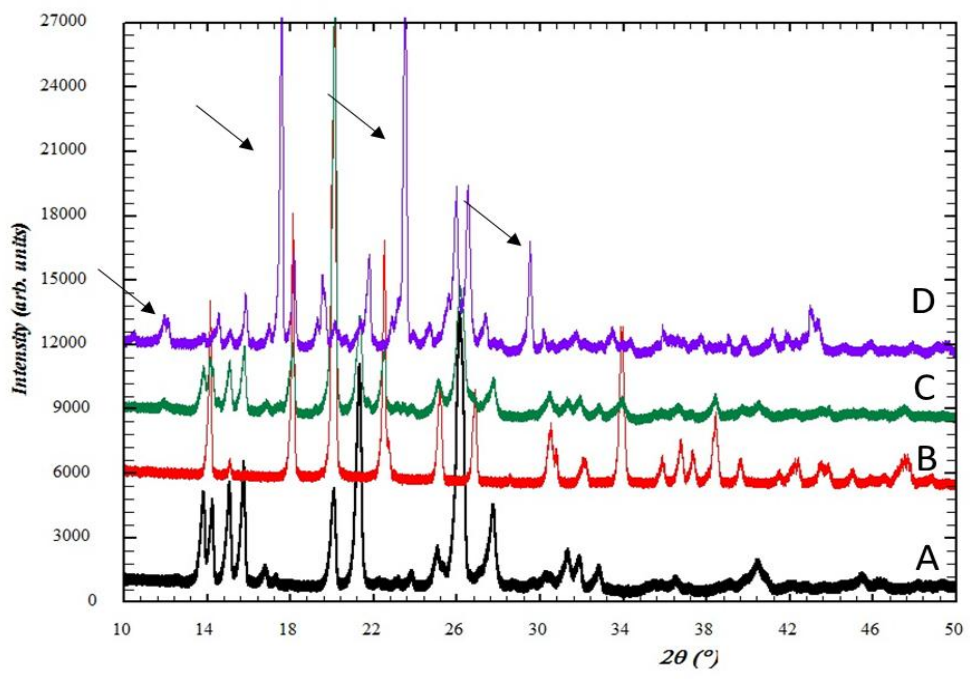

Figure 3. PXRD pattern of (A) mefenamic acid, (B) tromethamine, $(\mathbf{C})$ physical mixture of mefenamic acidtromethamine, and (D) multicomponent crystal of mefenamic acid-tromethamine.

The DSC thermal analysis was applied to characterize the solid-phase thermodynamic properties. Thermal analysis is also used to screen for the multicomponent crystal phase formation [34]. Herein, MA shows a sharp endothermic peak at $232.8^{\circ} \mathrm{C}$, which is the melting point of MA. Meanwhile, TM shows two endothermic peaks, at $137.1^{\circ} \mathrm{C}$ and $170.5^{\circ} \mathrm{C}$ (Fig. 4). The endothermic peak at $170.5^{\circ} \mathrm{C}$, is the melting point of $\mathrm{TM}$, whereas at $137.1^{\circ} \mathrm{C}$ is a temperature of a solid-state transition [24]. The multicomponent crystal shows a single endothermic peak $\left(110^{\circ} \mathrm{C}\right)$ which is different from the two constituent components. The melting point of the multicomponent crystal of MA-TM was lower than intact MA. The melting point of the molecular crystal of active pharmaceutical ingredients is correlated with the lattice energy of its crystalline phase. In general, the lower the melting point of a solid phase, the lower the lattice energy. The low lattice energy of a crystalline phase would allow it to dissolve faster in aqueous medium $[35,36]$.

FT-IR spectroscopy analysis is widely used to evaluate the solid-state interaction within multicomponent crystal systems. The changes and shifts of absorption bands in the FT-IR spectra indicate an inter-intramolecular bonding and interaction between drug and co-former in the crystal lattice [37]. FT-IR spectra of MA and MA-TM are presented in Fig. 5. MA demonstrates some characteristic absorption peaks for at wavenumbers $3306.45 \mathrm{~cm}^{-1}(-\mathrm{NH}), 2859.20 \mathrm{~cm}^{-1}(-\mathrm{CH} 3), 1643.81$ and $1576.66 \mathrm{~cm}^{-1}(-\mathrm{COOH})$, and 1436.90 , 1243.77 , and $1160.69 \mathrm{~cm}^{-1}$ (symmetric deformation vibrations of -CH3 group) [38]. Interestingly, the spectrum shows that the stretching vibration of the carbonyl group of $\mathrm{COOH}$ previously seen in MA at $1643.81 \mathrm{~cm}^{-1}$ is 
shifted to a lower wavenumber in the multicomponent crystal $\left(1558 \mathrm{~cm}^{-1}\right)$. This change shows a stretching vibration of the carboxylate anion ( $\left.\mathrm{COO}^{-}\right)$. Therefore, according to the data, it is assumed that solid-state interactions of MA-TM might involve proton transfer from MA molecules to TM molecules. This phenomenon is very reasonable because the $\mathrm{p} K_{\mathrm{a}}$ difference between MA and TM is quite significant $(3.87)[11,32]$.

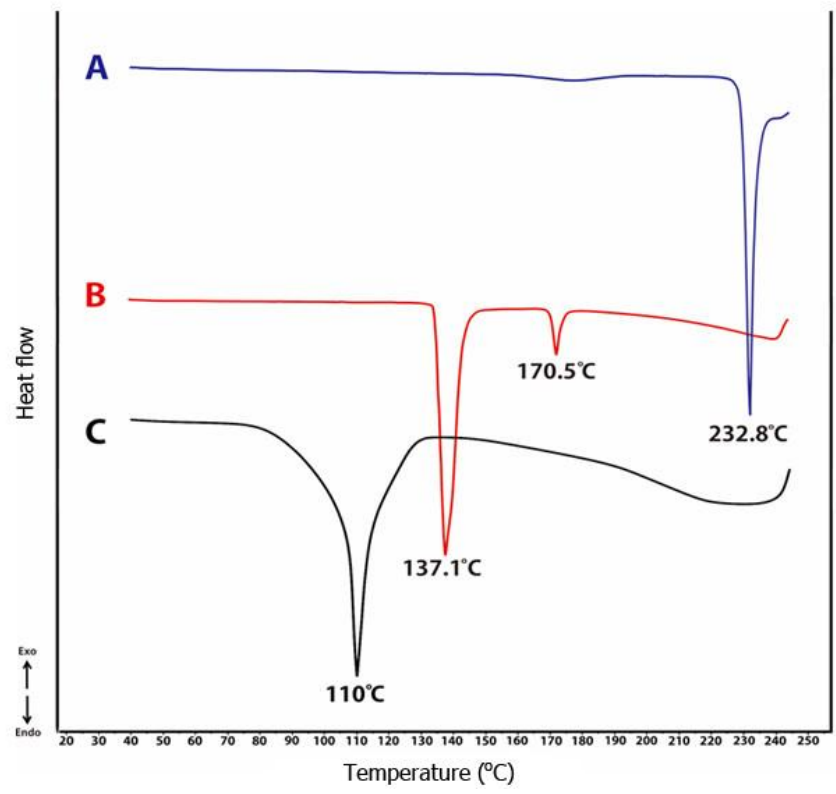

Figure 4. DSC thermogram of (A) mefenamic acid, (B) tromethamine, and (C) multicomponent crystal of mefenamic acid-tromethamine.

In general, there are two approaches to enhance the solubility and dissolution rate of poorly soluble drugs: 1) physicochemical properties modification of solid drug substances, and 2) manufacturing process and formulation strategies [39]. The formation of multicomponent crystals of MA-TM is an interesting approach to improving the dissolution rate of MA, which is a poorly soluble drug. Dissolution rate and bioavailability of the solid dosage form of MA are influenced by solid-state properties such as polymorphic properties, hydrophobicity and its particle size [40,41]. In addition, MA undergoes a phase transition due to mechanical stress and high relative humidity. This causes a transformation of form II of MA to form I which is less soluble $[42,43]$. In the current study, we report the formation of a new salt-type multicomponent crystal of MA-TM with an increased dissolution rate and dissolution efficiency. The dissolution rates of MA-TM and intact MA are demonstrated in Fig. 6, while the dissolution efficiency is presented in Table 1. The dissolution efficiency of salt-type multicomponent crystal MA-TM was 2.5-fold higher than intact MA. Furthermore, the dissolution efficiency was also significantly enhanced. The salt formation is proven to improve the physicochemical properties of APIs, especially the solubility and dissolution rate. Previous studies have reported an increase in solubility and dissolution rate of MA via multicomponent crystal phase with some excipients such as nicotinamide, cytosine, pyridine derivative [44-46].

Table 1. Comparative analysis of dissolution efficiency between multicomponent crystal of MA-TM and intact MA.

\begin{tabular}{lcccc}
\hline \multicolumn{1}{c}{ Materials } & $\begin{array}{c}\text { Dissolution } \\
\text { efficiency (\%) }\end{array}$ & Average & t-value & $p$-value \\
\hline Intact mefenamic acid (MA) & 28.37 & $28.75 \pm 0.666$ & -46.314 & 0.000 \\
& 28.37 & & \\
& 29.52 & & \\
Multicomponent crystal of & 74.41 & $75.99 \pm 1.636$ & \\
mefenamic acid with tromethamine & 75.90 & & \\
(MA-TM) & 77.67 & & \\
\hline
\end{tabular}

Average data are presented as mean \pm standard deviation, statistical analysis was conducted by independent $\mathrm{t}$-test $(95 \%$ confidence interval). 


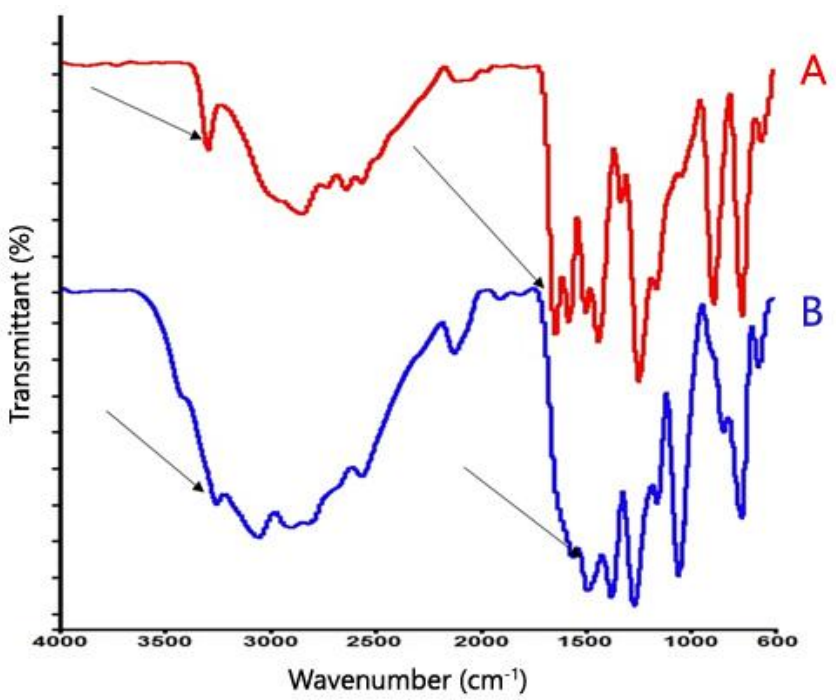

Figure 5. FT-IR spectra of (A) mefenamic acid, and (B) multicomponent crystal of mefenamic acidtromethamine.

There are several factors that might contribute to increasing the dissolution rate of a multicomponent crystal of MA-TM. First, salt type multicomponent crystal of MA-TM has a better affinity for the aqueous medium because the solid phase is more hydrophilic. When in contact with the aqueous medium, the salt form will dissociate into cationic and anionic ions. Second, from a solid-state properties point of view, there were changes in the crystal structure and the melting point of the crystalline phase. The melting point of a crystalline solid is influenced by the lattice energy, which binds molecules in the unit cell. The lower the melting point of the solid phase, the weaker the lattice energy of the crystalline phase. Hence, the dissolution rate is faster $[18,24,33,36]$.

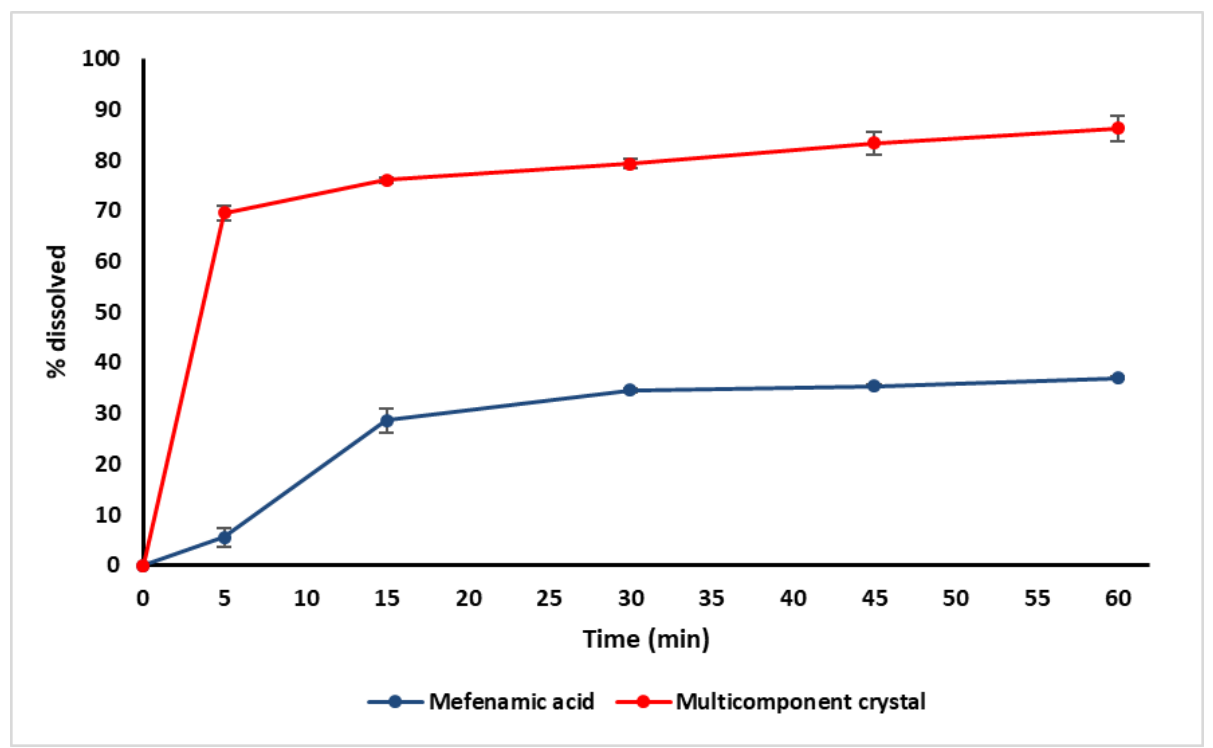

Figure 6. In vitro dissolution rate profile mefenamic acid and multicomponent crystal of mefenamic acidtromethamine.

\section{CONCLUSION}

A new salt-type multicomponent crystal of mefenamic acid-tromethamine is successfully prepared using the solvent co-evaporation technique. This multicomponent crystal shows remarkable changes in thermodynamic and crystallographic properties. Notably, the dissolution rate and dissolution efficiency of the salt-type multicomponent crystals of mefenamic acid-tromethamine are significantly higher than intact mefenamic acid. 


\section{MATERIALS AND METHODS}

\subsection{Materials}

Mefenamic acid was kindly provided by Indofarma Ltd. (Indonesia). Tromethamine was purchased from Merck (Germany). Organic solvents and chemicals were of analytical grade and used without further purification.

\subsection{Experimental Methods}

\subsubsection{Preparation of multicomponent crystal of $M A-T M$}

An equimolar amount of the multicomponent crystals of MA-TM was prepared by the solvent coevaporation technique. MA was dissolved in ethanol, while TM was dissolved in distilled water. Both were mixed and stirred until clear. The solution was evaporated at room temperature for 48 hours. Fine needle crystals were collected and stored in a desiccator for further characterization. As a comparator for PXRD analysis, an equimolar physical mixture of MA-TM was also prepared through a gentle mixing by spatula for 10 minutes.

\subsubsection{Scanning Electron Microscopy Analysis}

SEM microphotos were obtained by using an SEM apparatus (HITACHI type S-3400N, Japan). Sample powders were placed on an aluminum sample holder and all samples were sputtered with a thin film of goldpalladium. The measurements were obtained with the following conditions: $10 \mathrm{kV}$ voltage and $12 \mathrm{~mA}$ current.

\subsubsection{Powder X-ray Diffraction (PXRD) Analysis}

PXRD analysis was performed at room temperature with a PANanalytical PW 30/40 X-ray diffractometer (the Netherlands). The diffractogram was recorded from $2 \theta=10^{\circ}$ to $50^{\circ}$. The X-ray diffractometer was programmed as follow; target metal $\mathrm{Cu}$, Ka filter, voltage $45 \mathrm{kV}$ and current $40 \mathrm{~mA}$.

\subsubsection{Differential Scanning Calorimetry (DSC) Analysis}

DSC thermal analyses of MA, TM and MA-TM were conducted using a DSC apparatus (SETARAM Type EVO-131, France) which was calibrated using indium. Approximately $5 \mathrm{mg}$ of each sample was placed in an aluminum pan, and the temperature of measurement was set from 40 to $250{ }^{\circ} \mathrm{C}$ with a heat flow of 10 ${ }^{\circ} \mathrm{C} /$ minute. Nitrogen was used with a flow rate of $10-20 \mathrm{~mL} / \mathrm{min}$.

\subsubsection{Fourier Transform Infrared (FT-IR) Spectroscopy Analysis}

The FT-IR spectra of MA and MA-TM were generated by an FT-IR spectrophotometer (Perkin Elmer FT-IR, USA). The sample was mixed with potassium bromide in a weight ratio of 1:100. The mixture was then compressed into pellets. The absorption of samples was recorded at wavenumbers $4000-600 \mathrm{~cm}^{-1}$. The analysis was performed for MA and MA-TM.

\subsubsection{In vitro Dissolution Rate Study}

In vitro dissolution rate profiles of MA and MA-TM was determined by using dissolution testing equipment type I USP (Copley Scientific NE4-COPD, UK). The equipment was adjusted at a speed of $50 \mathrm{rpm}$ in $900 \mathrm{~mL}$ dissolution medium of phosphate buffer solution $(\mathrm{pH} 7.4)$ containing $0.5 \%$ sodium lauryl sulfate. The temperature was maintained at $37 \pm 0.5^{\circ} \mathrm{C}$. At predetermined times $(0,5,15,30,45$ and 60 minutes), approximately $5 \mathrm{~mL}$ of the aliquot was withdrawn and filtered. The concentration of MA in the medium was determined using a UV-vis spectrophotometer at a maximum absorption wavelength of $238.5 \mathrm{~nm}$. The experiment was run in triplicate. The data were presented in a chart (time vs percent of dissolved MA). The dissolution efficiency was calculated in accordance with an equation proposed by Khan in 1975 [47] and analyzed statistically by using independent $t$ test with $95 \%$ confidence interval.

Author contributions: Conceptualization - E.Z.; Design, E.Z.; Supervision - H.R.; E.Z.; Materials - R.I.; E.Z.; Data Collection and/or Processing - Y.Y.; R.I.; H.R.; E.Z.; Analysis and/or Interpretation - Y.Y.; R.I.; E.Z.; Literature Search - Y.Y.; R.I.; H.R.; E.Z.; Writing - Y.Y.; R.I.; E.Z.; Critical Reviews - Y.Y.; R.I.; H.R.; E.Z.

Conflict of interest statement: All authors declare no conflict of interest. 


\section{REFERENCES}

[1] Cimolai N. The potential and promise of mefenamic acid. Expert Rev Clin Pharmacol. 2013; 6(3): 289-305. [CrossRef]

[2] Joo Y, Kim HS, Woo RS, Park CH, Shin KY, Lee JP, Chang KA, Kim S, Suh YH. Mefenamic acid shows neuroprotective effects and improves cognitive impairment in in vitro and in vivo alzheimer's disease models. Mol Pharmacol. 2005; 69(1): 76-84. [CrossRef]

[3] Rawashdeh NM, Najib NM, Jalal IM. Comparative bioavailability of two capsule formulations of mefenamic acid. Int J Clin Pharmacol Ther. 1997; 35(8): 329-333.

[4] Konnerth C, Braig V, Ito A, Schmidt J, Lee G, Peukert W. Formation of mefenamic acid nanocrystals with improved dissolution characteristics. Chemie Ing Tech. 2017; 89(8): 1060-1071. [CrossRef]

[5] Gao P, Shi Y. Characterization of supersaturatable formulations for improved absorption of poorly soluble drugs. AAPS J. 2012; 14(4): 703-713. [CrossRef]

[6] Martinez MN, Amidon GL. A mechanistic approach to understanding the factors affecting drug absorption: A review of fundamentals. J Clin Pharmacol. 2002; 42(6): 620-643. [CrossRef]

[7] Zolkepali NK, Abu bakar NF, Naim MN, Anuar N, Kamalul Aripin NF, Abu Bakar MR, Lenggoro IW, Kamiya H. Formation of fine and encapsulated mefenamic acid form I particles for dissolution improvement via electrospray method. Part Sci Technol. 2018; 36(3): 298-307. [CrossRef]

[8] Andrews GP, Zhai H, Tipping S, Jones DS. Characterisation of the thermal, spectroscopic and drug dissolution properties of mefenamic acid and polyoxyethylene-polyoxypropylene solid dispersions. J Pharm Sci. 2009; 98(12): 4545-4556. [CrossRef]

[9] Derle D V, Bele M, Kasliwal N. In vitro and in vivo evaluation of mefenamic acid and its complexes with $\beta$ Cyclodextrin and HP- $\beta$-Cyclodextrin. Asian J Pharm. 2008; 2(1): 30-34.

[10] Sriamornsak P, Limmatvapirat S, Piriyaprasarth S, Mansukmanee P, Huang Z. A new self-emulsifying formulation of mefenamic acid with enhanced drug dissolution. Asian J Pharm Sci. 2015; 10(2): 121-127. [CrossRef]

[11] Fang L, Numajiri S, Kobayashi D, Ueda H, Nakayama K, Miyamae H, Morimoto Y. Physicochemical and crystallographic characterization of mefenamic acid complexes with alkanolamines. J Pharm Sci. 2004; 93(1): 144-154. [CrossRef]

[12] Kaival P, Kulkarni PK, Dixit M, Kni AG. Influence of surfactants on crystal form of mefenamic acid. Thai J Pharm Sci 2011; 35(1): 40-50.

[13] Dixit M, Kini AG, Kulkarni PK. Enhancing the dissolution of polymorphs I and II of mefenamic acid by spray drying. Turkish J Pharm Sci 2012; 9(1): 13-26.

[14] Dixit M, Kulkarni PK. Enhancing solubility and dissolution of Mefenamic acid by freeze drying. Elixir Bio Phys 2011; 39: 5026-5029.

[15] Huang L-F, Tong W-Q. Impact of solid state properties on developability assessment of drug candidates. Adv Drug Deliv Rev. 2004; 56(3): 321-334. [CrossRef]

[16] Byrn SR, Zografi G, Chen XS. Accelerating proof of concept for small molecule drugs using solid-state chemistry. J Pharm Sci. 2010; 99(9): 3665-3675. [CrossRef]

[17] Blagden N, de Matas M, Gavan PT, York P. Crystal engineering of active pharmaceutical ingredients to improve solubility and dissolution rates. Adv Drug Deliv Rev. 2007; 59(7): 617-630. [CrossRef]

[18] Dwichandra Putra O, Umeda D, Fujita E, Haraguchi T, Uchida T, Yonemochi E, Uekusa H. Solubility improvement of benexate through salt formation using artificial sweetener. Pharmaceutics. 2018; 10(2): 64. [CrossRef]

[19] Ainurofiq A, Mauludin R, Mudhakir D, Umeda D, Soewandhi SN, Putra OD, Yonemochi E. Improving mechanical properties of desloratadine via multicomponent crystal formation. Eur J Pharm Sci. 2018; 111: 65-72. [CrossRef]

[20] Nugrahani I, Utami D, Ibrahim S, Nugraha YP, Uekusa H. Zwitterionic cocrystal of diclofenac and 1 -proline: Structure determination, solubility, kinetics of cocrystallization, and stability study. Eur J Pharm Sci. 2018; 117: 168176. [CrossRef]

[21] Yuliandra Y, Zaini E, Syofyan S, Pratiwi W, Putri L, Pratiwi Y, Arifin H. Cocrystal of ibuprofen-nicotinamide: Solidstate characterization and in vivo analgesic activity evaluation. Sci Pharm. 2018; 86(2): 23. [CrossRef]

[22] Zaini E, Fitriani L, Sari RY, Rosaini H, Horikawa A, Uekusa H. Multicomponent crystal of mefenamic acid and nmethyl-d-glucamine: Crystal structures and dissolution study. J Pharm Sci. 2019; 108(7): 2341-2348. [CrossRef] 
[23] Abdelkader H, Abdallah OY, Salem HS. Comparison of the effect of tromethamine and polyvinylpyrrolidone on dissolution properties and analgesic effect of nimesulide. AAPS PharmSciTech. 2007; 8(3): E110-E117. [CrossRef]

[24] Bruni G, Berbenni V, Maggi L, Mustarelli P, Friuli V, Ferrara C, Pardi F, Castagna F, Girella A, Milanese C, Marini A. Multicomponent crystals of gliclazide and tromethamine: preparation, physico-chemical, and pharmaceutical characterization. Drug Dev Ind Pharm. 2018; 44(2): 243-250. [CrossRef]

[25] Garekani HA, Sadeghi F, Badiee A, Mostafa SA, Rajabi-Siahboomi AR, Rajabi-Siahboomi AR. Crystal habit modifications of ibuprofen and their physicomechanical characteristics. Drug Dev Ind Pharm. 2001; 27(8): 803-809. [CrossRef]

[26] York P, Paradkar A. Crystal engineering and particle design for the powder compaction process. In: Pharmaceutical Powder Compaction Technology. 2nd Ed. CRC Press; 2016: 248-265.

[27] Basavoju S, Boström D, Velaga SP. Indomethacin-Saccharin Cocrystal: Design, Synthesis and Preliminary Pharmaceutical Characterization. Pharm Res. 2008; 25(3): 530-541. [CrossRef]

[28] Zaini E, Sumirtapura YC, Soewandhi SN, Halim A, Uekusa H, Fujii K. Cocrystalline phase transformation of binary mixture of trimethoprim and sulfamethoxazole by slurry technique. Asian J Pharm Clin Res. 2010; 3(4): 26-29.

[29] Aitipamula S, Vangala VR. X-ray crystallography and its role in understanding the physicochemical properties of pharmaceutical cocrystals. J Indian Inst Sci. 2017; 97(2): 227-243. [CrossRef]

[30] Kato F, Otsuka M, Matsuda Y. Kinetic study of the transformation of mefenamic acid polymorphs in various solvents and under high humidity conditions. Int J Pharm. 2006; 321(1-2): 18-26. [CrossRef]

[31] Grothe E, Meekes H, Vlieg E, ter Horst JH, de Gelder R. Solvates, salts, and cocrystals: A proposal for a feasible classification system. Cryst Growth Des. 2016; 16(6): 3237-3243. [CrossRef]

[32] Cruz-Cabeza AJ. Acid-base crystalline complexes and the pKa rule. CrystEngComm. 2012; 14(20): 6362. [CrossRef]

[33] Bookwala M, Thipsay P, Ross S, Zhang F, Bandari S, Repka MA. Preparation of a crystalline salt of indomethacin and tromethamine by hot melt extrusion technology. Eur J Pharm Biopharm. 2018; 131: 109-119. [CrossRef]

[34] Lu E, Rodríguez-Hornedo N, Suryanarayanan R. A rapid thermal method for cocrystal screening. Cryst Eng Comm. 2008. [CrossRef]

[35] Dwichandra Putra O, Yonemochi E, Uekusa H. Isostructural multicomponent gliclazide crystals with improved solubility. Cryst Growth Des. 2016; 16(11): 6568-6573. [CrossRef]

[36] Katritzky AR, Jain R, Lomaka A, Petrukhin R, Maran U, Karelson M. Perspective on the relationship between melting points and chemical structure. Cryst Growth Des. 2001; 1(4): 261-265. [CrossRef]

[37] Putra OD, Umeda D, Nugraha YP, Furuishi T, Nagase H, Fukuzawa K, Uekusa H, Yonemochi E. Solubility improvement of epalrestat by layered structure formation via cocrystallization. Cryst Eng Commun. 2017; 19(19): 2614-2622. [CrossRef]

[38] Topacli A, Ide S. Molecular structures of metal complexes with mefenamic acid. J Pharm Biomed Anal. 1999; 21(5): 975-982. [CrossRef]

[39] Kawabata Y, Wada K, Nakatani M, Yamada S, Onoue S. Formulation design for poorly water-soluble drugs based on biopharmaceutics classification system: Basic approaches and practical applications. Int J Pharm. 2011; 420(1): 110. [CrossRef]

[40] Adam A, Schrimpl L, Schmidt PC. Some physicochemical properties of mefenamic acid. Drug Dev Ind Pharm. 2000; 26(5): 477-487. [CrossRef]

[41] Shinkuma D, Hamaguchi T, Yamanaka Y, Mizuno N. Correlation between dissolution rate and bioavailability of different commercial mefenamic acid capsules. Int J Pharm. 1984; 21(2): 187-200. [CrossRef]

[42] Romero S, Escalera B, Bustamante P. Solubility behavior of polymorphs I and II of mefenamic acid in solvent mixtures. Int J Pharm. 1999; 178(2): 193-202. [CrossRef]

[43] Otsuka M, Kato F, Matsuda Y. Effect of temperature and kneading solution on polymorphic transformation of mefenamic acid during granulation. Solid State Ionics. 2004; 172(1-4): 451-453. [CrossRef]

[44] SeethaLekshmi S, Guru Row TN. Conformational Polymorphism in a Non-steroidal Anti-inflammatory Drug, Mefenamic Acid. Cryst Growth Des. 2012; 12(8): 4283-4289. [CrossRef]

[45] Fábián L, Hamill N, Eccles KS, Moynihan HA, Maguire AR, McCausland L, Lawrence SE. Cocrystals of Fenamic Acids with Nicotinamide. Cryst Growth Des. 2011; 11(8): 3522-3528. [CrossRef] 
[46] Nechipadappu SK, Trivedi DR. Structural and physicochemical characterization of pyridine derivative salts of antiinflammatory drugs. J Mol Struct. 2017; 1141: 64-74. [CrossRef]

[47] Khan KA. The concept of dissolution efficiency. J Pharm Pharmacol. 1975; 27(1): 48-49. [CrossRef]

This is an open access article which is publicly available on our journal's website under Institutional Repository at http://dspace.marmara.edu.tr. 